\title{
Surfactants enhanced recovery of endosulfan from contaminated soils
}

\author{
${ }^{* 2}$ R. Jayashree, ${ }^{1}$ N. Vasudevan and ${ }^{2}$ S. Chandrasekaran \\ ${ }^{1}$ Centre for Environmental Studies, Anna University, Chennai- 600 025, Tamil nadu, India \\ ${ }^{2}$ Department of Entomology, Tamilnadu Agricultural University, Coimbatore- 641 003, India \\ Received 2 January 2006; revised 24 May 2006; accepted 1 June 2006; available online 25 June 2006
}

\begin{abstract}
Soil pollution due to hydrophobic organic compounds is a wide environmental problem. Extensive use of endosulfan in cotton and paddy to meet the needs of the growing population has led to contamination of soil and other ecosystems. Endosulfan is hydrophobic, highly toxic to aquatic and human population and persists in soil for more than a year. To overcome the problem of hydrophobicity and limited availability, surfactants play a major role in soil remediation. In the present study, the potential of non-ionic synthetic surfactants (Tween 80, Triton X-100) and biosurfactant (Surfactin produced by Bacillus subtilis) for enhancing the release of endosulfan from contaminated agricultural soils was evaluated using the batch method. Incorporation of the surfactant concentrations at above Criticle Miceller Concentration (0.5, 1 and $2 \mathrm{~g} / \mathrm{L}$ ) into soil enhances the release of endosulfan. Surfactin produced from Bacillus subtilis recorded maximum (91.5\%) recovery. The observed order of recovery being surfactin $>$ Tween $80>$ Triton X-100. The result suggest that surfactants could help in the remediation of soils polluted by pesticides.
\end{abstract}

Key words: Surfactants, micelle, endosulfan , remediation, Bacillus subtilis

\section{INTRODUCTION}

The use of pesticides in agriculture has increased substantially during the past few decades, to increase the crop production and to meet the needs of the growing population. The broad spectrum insecticide endosulfan (6, 7, 8, 9, 10-hexachlor-1, 5, 5a, 6, 9, 9ahexahydro-6, 9-methano-2, 3, 4-benzo dioxathiepin-3oxide), currently used throughout the world on a variety of vegetables, fruits, cereals and cotton as well as shrubs, trees, vines and ornamentals for use in commercial agricultural region (Kullman and Matsumura, 1996). Endosulfan is currently registered to control insects, mites on 60 crops. Total average annual use of endosulfan is estimated to be 1.38 million pounds of active ingredients. Endosulfan is a Persistent Organic Pollutant (POP) that enters the air, water and soil during its use and manufacture. Endosulfan and its break down products are persistent in the environment with an estimated half-life of 9 months to 6 years. Endosulfan has been ubiquitously detected in atmosphere, soil, sediments and ground water (Turner et al., 1997). It is one of the most commonly detected pesticides in ground and surface waters of India. Technical grade endosulfan comprises

*Corresponding author, Email: p_tamil@yahoo.com

Tel.: +9198-4069 5341; Fax: +9198-4069 5341 of two stereo isomers, $\alpha$ and $\beta$-endosulfan in a ratio of $7: 3$, low soluble in water and both of the isomers are extremely toxic to fish and aquatic organisms (Sunderam et al., 1992). Endosulfan affects the central nervous system, kidney, liver, blood chemistry and parathyroid gland and has reproductive tetragenic and mutagenic effects (Paul and Balasubramaniam, 1997). Bioavailability of endosulfan was limited by its sequestration in soil organic matter (SOM) and incorporation in the soil micropores due to its long contact with soil matrix. Therefore it is important to find a way to enhance the release of the aged endosulfan from long term contaminated soils. Surfactants (surface active agents) increase the concentration of a hydrophobic compound in the aqueous phase by emulsification and solubilization. Surfactants are amphiphilic compound powering both hydrophobic and hydrophilic moieties. A phenomenon unique to surfactants is the self-assembly of molecules into dynamic clusters called micelles. Micelle formation occurs above a critical concentration of surfactant monomers referred to as the critical micelle concentration (CMC). Incorporation of hydrophobic compound in the micelles is termed as solubilization. Solubilization and lowering of the surface and interface tension are thought to be the main reasons for 
facilitated transport of pollutants adsorbed on solid phases to the surfactant containing aqueous phase. Washing with surfactant solution has been shown to be effective for the removal of hydrophobic compounds (Tiehm et al., 1997). Several attempts to enhance the bioavailability of hydrocarbons by the use of surfactants have been made (Arenstein et al., 1991; Bury and Miller, 1993 and Laha and Luthy, 1996). In some studies, especially the structure and physicochemical properties of surfactants leading to toxicity are a question of intensive discussion. It was recently reported that non-ionic surfactants were non-toxic to soil microorganisms (Thibault et al., 1994). The aim of this study was to test the recovery of endosulfan from soils of Thiruvallur district. The lab study was carried out in Centre for Environmental Studies, Anna University, Chennai during the month of March, 2005 with two non-ionic surfactants Triton X-100, Tween 80 and one bio surfactant surfactin from Bacillius subtilis obtained from MTCC 1427. Biosurfactants are structurally diverse compounds, mainly produced by hydrocarbon utilizing microorganisms which exhibit surface activity. Biosurfactants are biodegradable, nontoxic or less toxic than chemical surfactants. Their properties of interest are i) changing surface-active phenomena such as lowering of surface and interfacial tensions. ii) wetting and penetrating actions. iii) spreading. iv) hydrophilicity and hydrophobicity actions. v) microbial growth enhancement and vi) antimicrobial action (Kosaric, 2001). The surfactin produced from Bacillus subtilis is known for its ability to produce surface active compounds. The soluble substrate sucrose, resulted in higher biosurfactant production.

\section{MATERIALS AND METHODS}

\section{Chemicals}

Endosulfan standards were purchased from M/s. Chem Service Inc., West Chester, USA. With a purity of 98-99\%: $\alpha$-endosulfan, $\beta$-endosulfan, endosulfan sulfate. A standard was prepared by dilution of the stock solution (1000 mg/mL) of each compound and stored in the refrigerator at $4{ }^{\circ} \mathrm{C}$. All stock solutions were stored at $-20^{\circ} \mathrm{C}$. Hexane and other solvents and chemicals used in this study were of analytical grade. Commercial endosulfan was purchased from Jayaprakash Fertilizers Agency, Thiruvallur district. The non-ionic surfactants (Tween 80 and Triton X100) were obtained from Sigma Chemical Co., USA. Bacillus subtilis for the production of surfactin was procured from Microbial Type Culture Collection (MTCC), Chandigarh, India. All other reagents used in the study were of analytical grade

\section{Biosurfactant production}

Bacillus subtilis was obtained from MTCC (Cat. No.1427) Chandigarh was grown on nutrient agar medium (peptone $5.0 \mathrm{~g}$, sodium chloride $5.0 \mathrm{~g}$, beef extract $1.5 \mathrm{~g}$, agar powder $15 \mathrm{~g}$, distilled water $1.0 \mathrm{~L}, \mathrm{pH}$ $7.2 \pm 0.2$ ). One $\mathrm{mL}$ of $24 \mathrm{hr}$. old culture was transferred to an Erlenmeyer flask containing $100 \mathrm{~mL}$ of the mineral medium (sucrose $10 \mathrm{~g}$, diammonium sulphate $1.0 \mathrm{~g}$, disodium hydrogen orthophosphate $6.0 \mathrm{~g}$, potassium dihydrogen orthophosphate 3.0 g, sodium chloride 27 g, magnesium sulphate $0.6 \mathrm{~g}$, trace element solution 5 $\mathrm{mL}$ (Meyer and Fietcher, 1985). The culture was maintained at $30{ }^{\circ} \mathrm{C}$ under shaking condition at 150 rpm. The biosurfactant released into the medium were determined upto 48 hr. Purification and other procedures were done by following the method of Moran et al., (2000).

\section{Determination of CMC}

CMC of each of the surfactant used in the study was determined by measuring the surface tension of the aqueous solution of each surfactant over a wide range of aqueous concentrations and noting the inflection in the plot of surface tension vs log surfactant concentration. The plotted surface tension value was taken, when stable readings were obtained for a given concentration of surfactant (Miller and Zhang, 1997).

\section{Surfactant mediated endosulfan recovery studies}

The rate and extent of recovery of endosulfan from contaminated soil in the presence of surfactants were measured in batch studies. The soil used in this study was collected from Thiruvallur district with no history of endosulfan contamination. The soil samples were analysed for basic soil characteristics like nitrogen (Subbiah and Asija, 1956), phosphorous (Olsen et al., 1954), potassium (Stanford and English, 1948), bulk density (Chopra and Kanwar, 1982), moisture content, organic carbon (Walkley and Black, 1934), calcium, magnesium (Jackson, 1958), pH and humic acid content (Stevenson, 1956). The soil was sterilized by autoclaving $\left(121^{\circ} \mathrm{C}\right.$ at $\left.15 \mathrm{psi}\right)$ for $1 \mathrm{~h}$ beforehand. After autoclaving, the soil was incubated on nutrient agar medium at $36{ }^{\circ} \mathrm{C}$ for $48 \mathrm{~h}$ and no microbial growth was 
observed. For the artificial contamination of endosulfan into the soil, endosulfan at different concentrations 10, 20, 40, 80, 120 and $160 \mathrm{mg}$ dissolved in ethyl acetate and then poured onto the $\mathrm{kg}$ of soil. The ethyl acetate was evaporated under a hood before the experiment. After complete evaporation, the contaminated soil mixed with surfactant solutions Tween 80 (Ethoxy sorbitol trioleate ether), Triton X100 (nonylphenol polyethoxyethylene ether) and surfactin at $0.5,1$ and $2 \mathrm{~g} / \mathrm{L}$ in the ratio of $1: 10$ in screw caped bottles. Three replicates were maintained for each concentrations. The bottles were equilibrated for about $48 \mathrm{~h}$. at $30^{\circ} \mathrm{C}$ on a rotary shaker (125 rpm). Samples were collected at every 6, 12, 24, 36 and $48 \mathrm{~h}$. The samples were centrifuged for 20 minutes at $10000 \mathrm{rpm}$ to separate the undissolved portion of the endosulfan.

\section{Extraction of endosulfan residues from aqueous samples}

An aliquot of $10 \mathrm{~mL}$ of each supernatant was transfered to a separating funnel for liquid-liquid extraction with hexane $(50 \mathrm{~mL})$. The hexane layer was separated and used for further analysis. This process was repeated thrice with the same sample, to ensure complete extraction of pesticide residues. These three extracts were pooled and passed through a column of anhydrous sodium sulphate (5 g) and florisil (2 g) mixture with glass wool at the bottom to remove the fatty and any other remaining water molecules. The sample was concentrated using Buchi condenser and $2 \mathrm{~mL}$ was collected (Veeraiah and Durgaprasad. 1996).

\section{Gas chromatographic analysis}

One microlitre from each of the final residue solutions was injected into the GC 1000 (Chemito) chromatograph equipped with OV-17 glass column (4'x1/8", filled with $60-80$ mesh coated with a mixture of $1.5 \%$ OV-17 and 1.95\% OQ) with ECD (Electron Capture Detector) for endosulfan residue analysis with an injector temperature of $220{ }^{\circ} \mathrm{C}$, oven temperature $190{ }^{\circ} \mathrm{C}$, detector temperature $280{ }^{\circ} \mathrm{C}$ and nitrogen as carrier gas $(27 \mathrm{~mL} / \mathrm{min})$. The qualitative identification of the endosulfan residues present in the real samples was performed by comparing the relative retention times (RRT) with respect to the internal standard, for each peak in the real sample chromotogram to those (RRT) in the standard mixture chromotogram. The quantitative determination was performed by using the relative peak areas (RPA) and the relative concentrations (RC).

\section{RESULTS}

The basic physical and chemical characteristics of soil presented in Table 1. The $\mathrm{pH}$ of the soil used in this investigation was near neutral in nature 7.5. The mechanical analysis of soil showed that the soil was sandy loam type with low clay and organic matter contents. Hence, the soil is fairly good to conduct the research for the role of surfactants to recover the endosulfan used in soil environment where clear changes could be visualized.

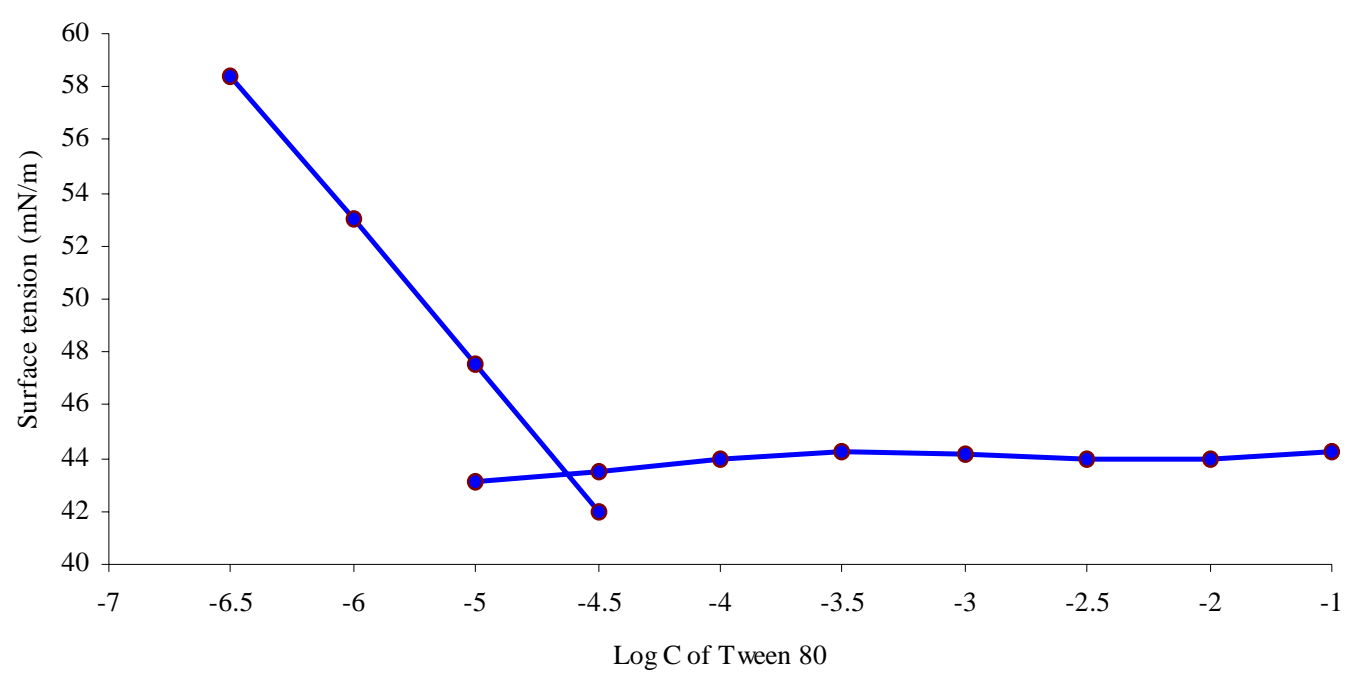

Fig. 1: Criticle micelle concentration of Tween 80 
R. Jayashree, et al.

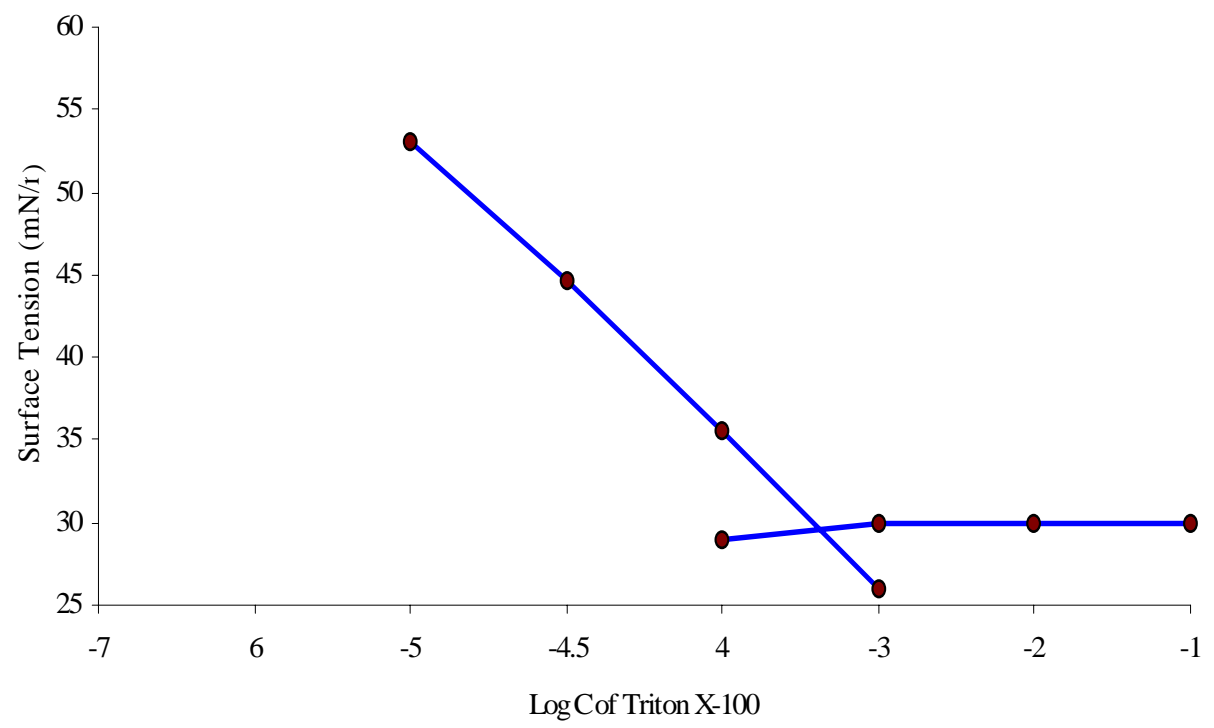

Fig. 1a: Criticle micelle concentration of Triton X-100

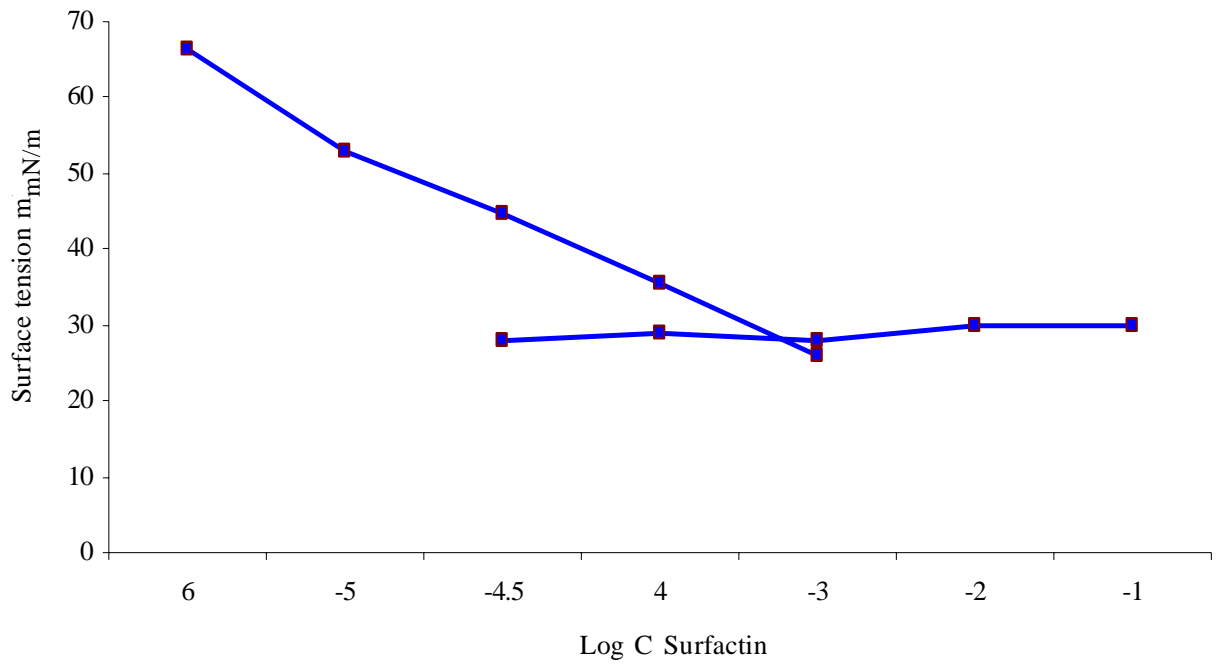

Fig. 1b: Criticle micelle concentration of Surfactin

\section{Critical micelle concentration}

The CMC values for Triton X-100, Tween 80 and surfactin were $13.4 \mathrm{mg} / \mathrm{L}, 13.6 \mathrm{mg} / \mathrm{L}$ and $20 \mathrm{mg} / \mathrm{L}$ respectively (Fig. 1). The CMC is an important property in terms of remediation because above this concentration, surfactants may greatly increase the water solubility of organic contaminants due to the increased numbers of micelles (Rosen, 1989). Selected concentrations $(0.5,1$ and $2 \mathrm{~g} / \mathrm{L}$ ) of surfactants were used in the present study.

\section{Recovery of endosulfan by surfactants}

The release of endosulfan, which is a very hydrophobic compound (aqueous solubility $0.3 \mathrm{mg} / \mathrm{L}$ ) was dramatically enhanced by the aqueous concentrations of surfactants above their CMC values. The effect of surfactants on the recovery of endosulfan is presented in Figs. 2, 3, 4, 5, 6 and 7. The three surfactants, at all concentrations, appreciably increased the extent of the release of endosulfan as compared to solutions with no surfactant. 


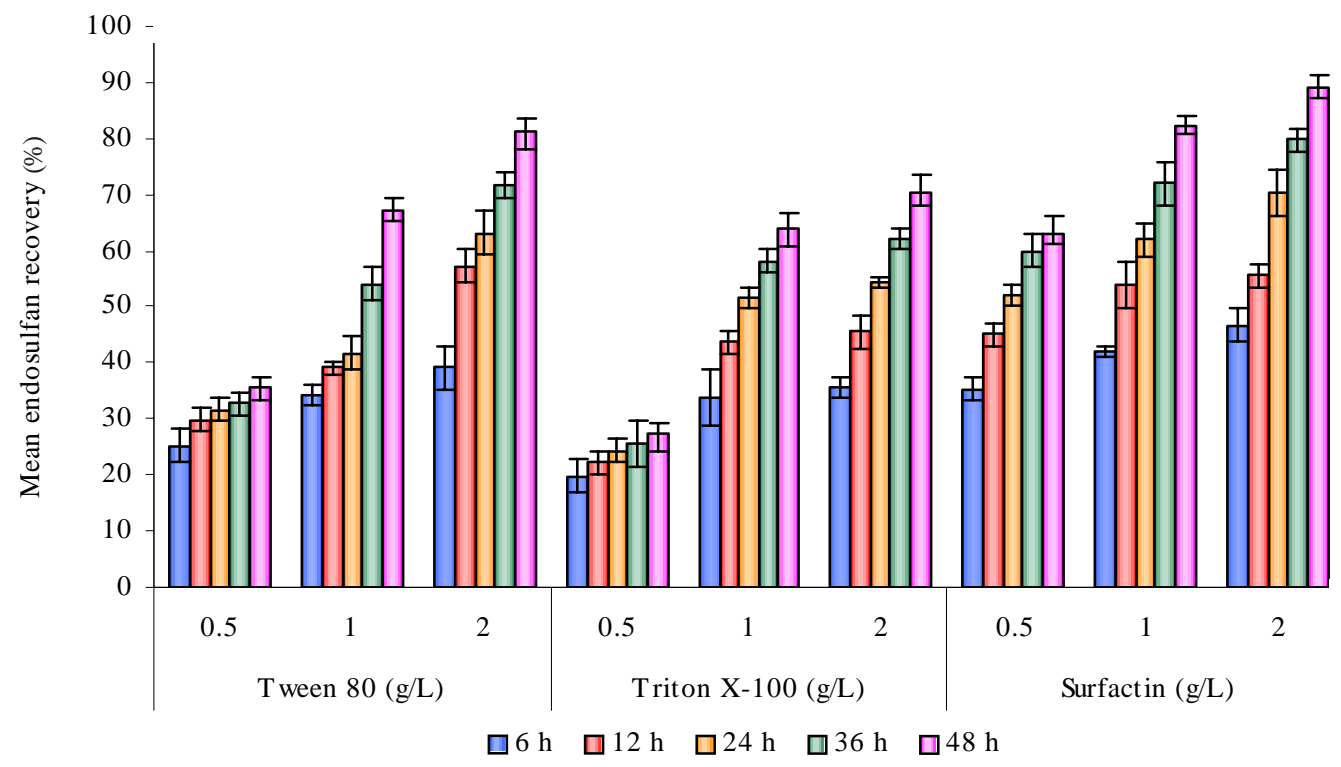

Fig. 2: Surfactants enhanced recovery of endosulfan $(10 \mathrm{mg} / \mathrm{kg})$ contaminated soil

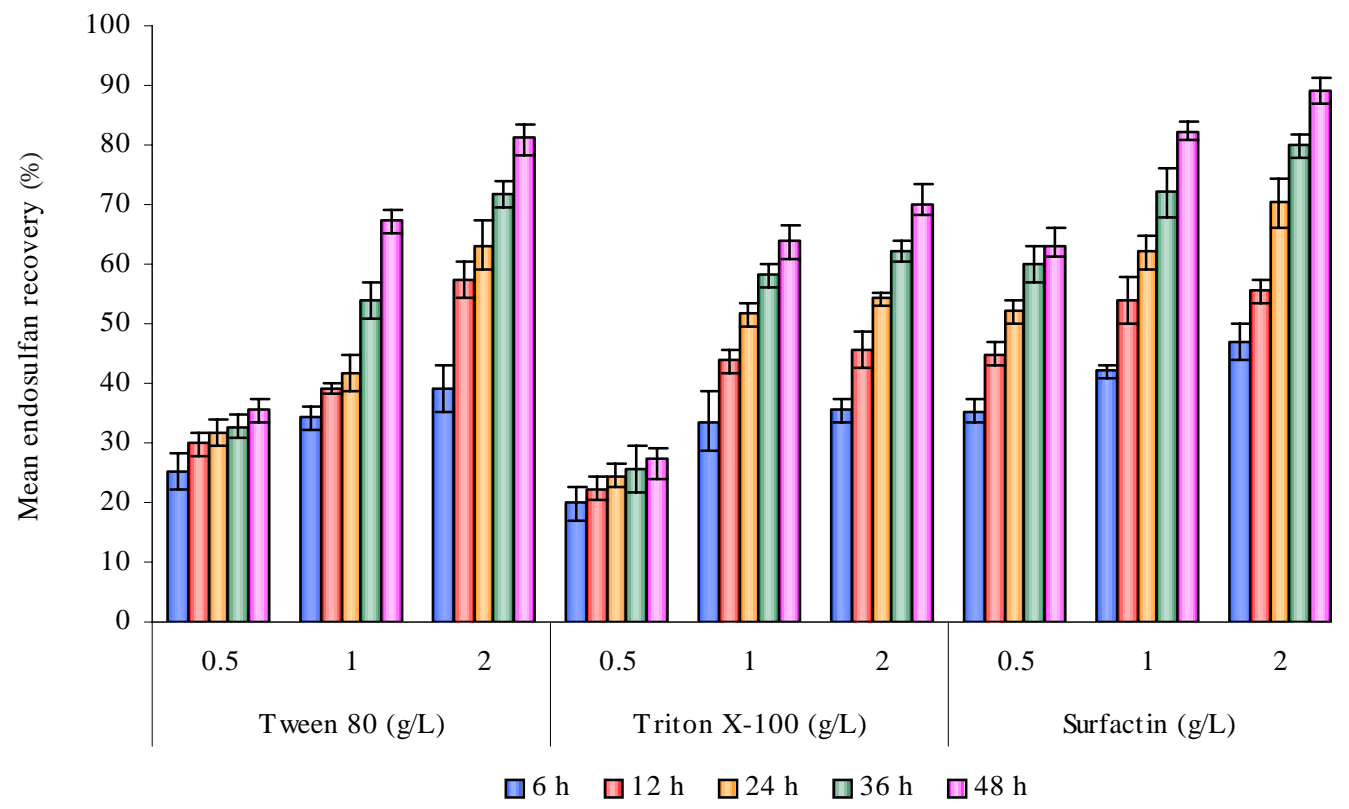

Fig. 3: Surfactants enhanced recovery of endosulfan $(20 \mathrm{mg} / \mathrm{kg})$ contaminated soil

This is attributed to solubility enhancement through incorporation of the highly hydrophobic compound within surfactant micelles (Edwards et al., 1991). Surfactin was the most effective to remove the adsorbed endosulfan. A concentration of $2 \mathrm{~g} / \mathrm{L}$ surfactin released $91.5 \%$ of the endosulfan from the soil on $48 \mathrm{hr}$. During the first $6 \mathrm{hr}$. maximum (30-40\%) amount of recovery was observed and then recovery process was very slow. When compared to 0.5 and $1 \mathrm{~g} / \mathrm{L}, 2 \mathrm{~g} / \mathrm{L}$ concentrations recorded maximum recovery in all the three surfactant studied. The recovery per cent at $0.5 \mathrm{~g} / \mathrm{L}$ was $62.05 \%$ and $1 \mathrm{~g} / \mathrm{L}$ was $82.60 \%$. Among the synthetic surfactants, a significant amount of recovery (upto $86 \%$ ) was contributed by Tween 80. However, there was still a significant portion of endosulfan left in soil which may be bound or logged into soil matrix. 
R. Jayashree, et al.

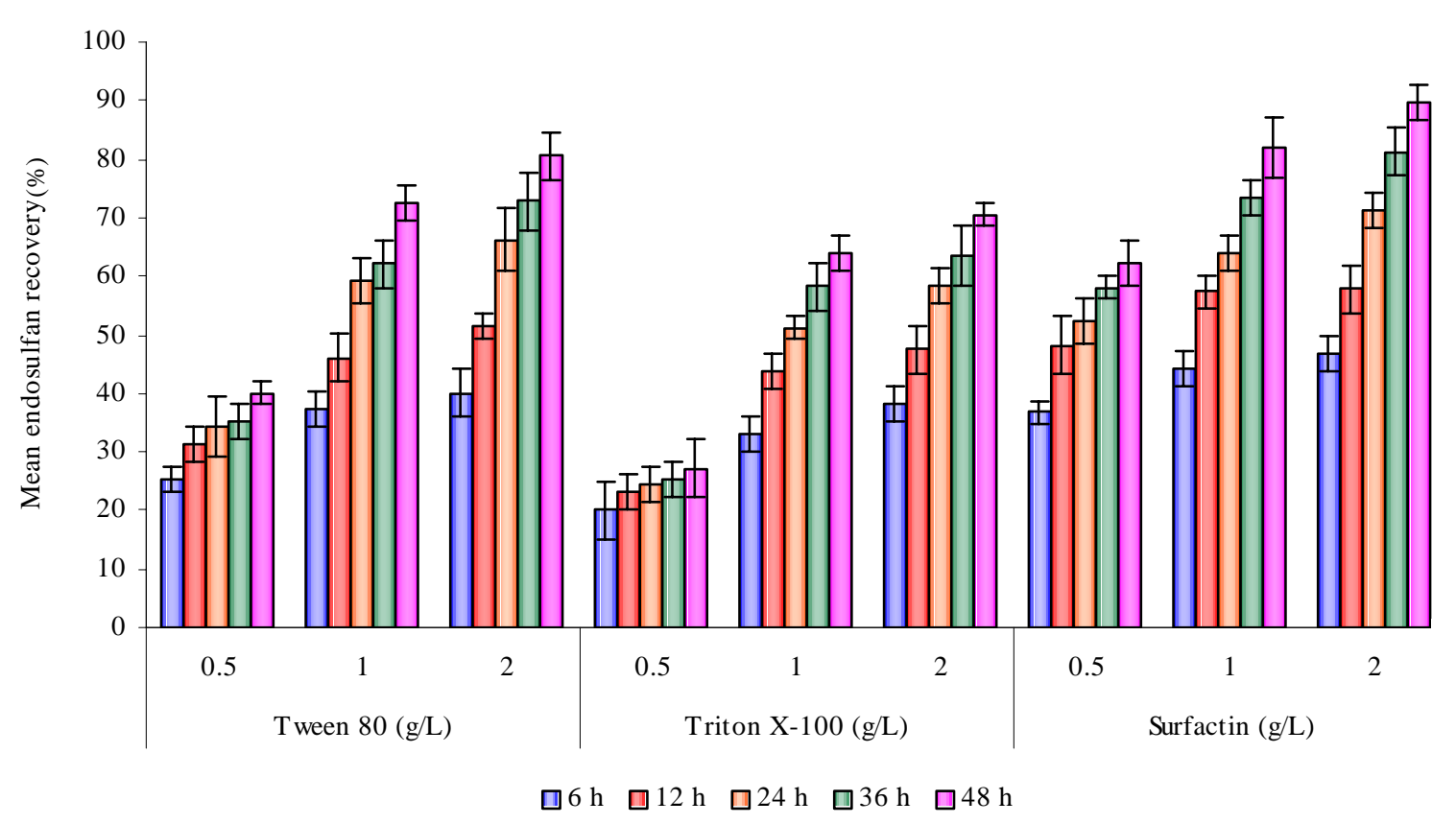

Fig. 4: Surfactants enhanced recovery of endosulfan $(40 \mathrm{mg} / \mathrm{kg})$ contaminated soil

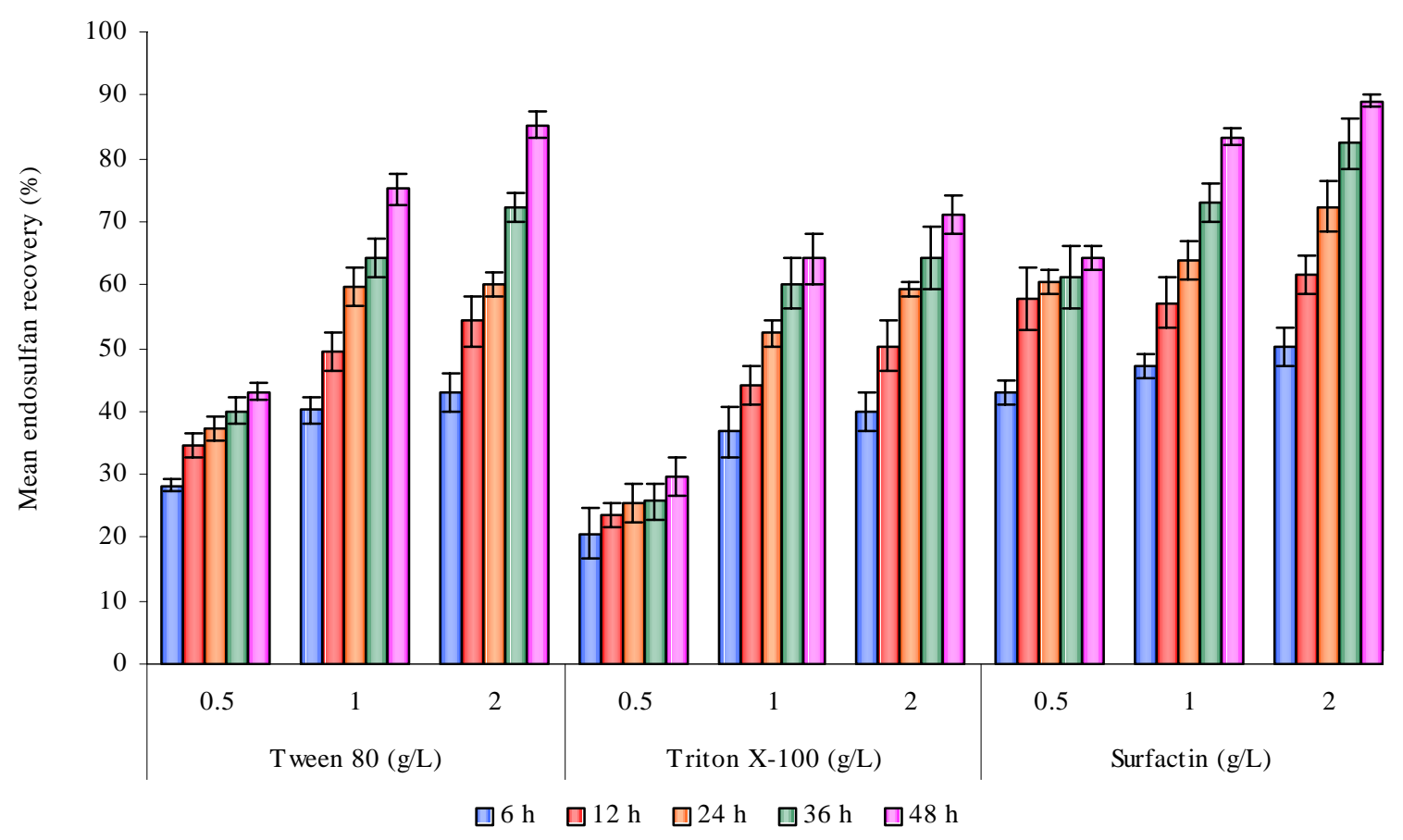

Fig. 5: Surfactants enhanced recovery of endosulfan $(80 \mathrm{mg} / \mathrm{kg})$ contaminated soil 


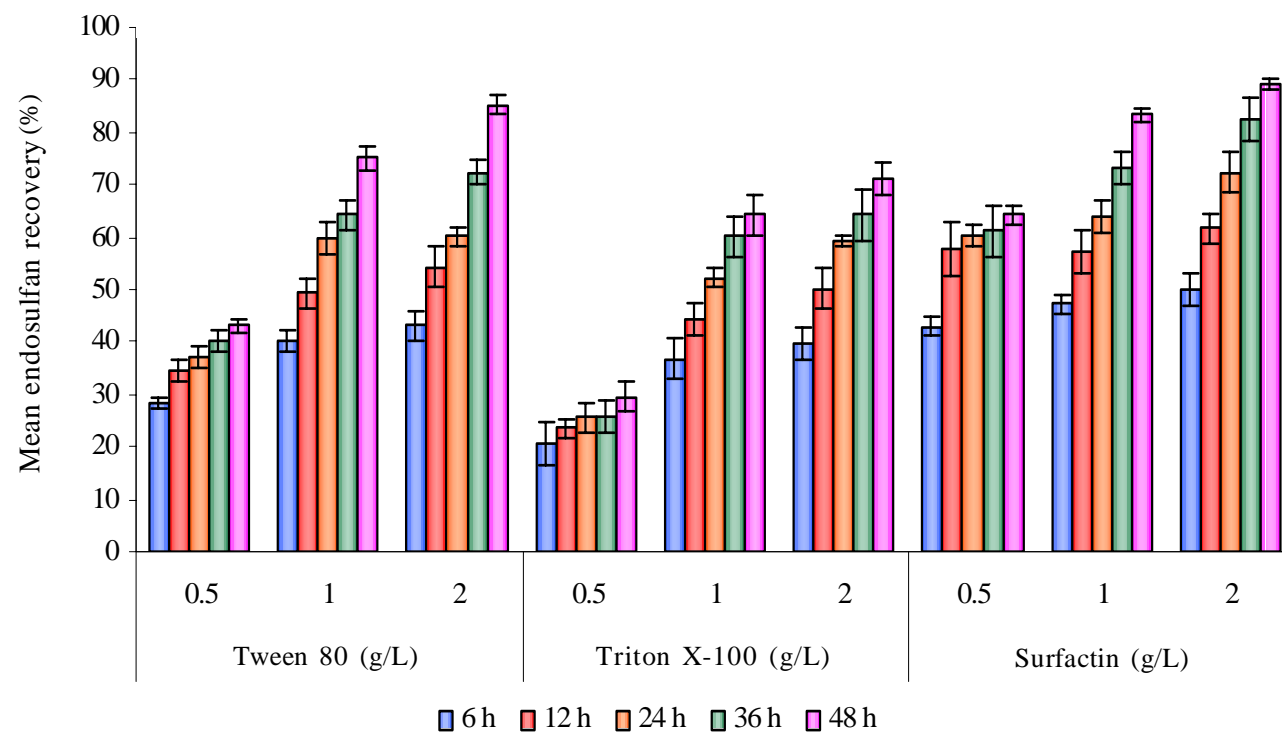

Fig. 6: Surfactants enhanced recovery of endosulfan $(120 \mathrm{mg} / \mathrm{kg})$ contaminated soil

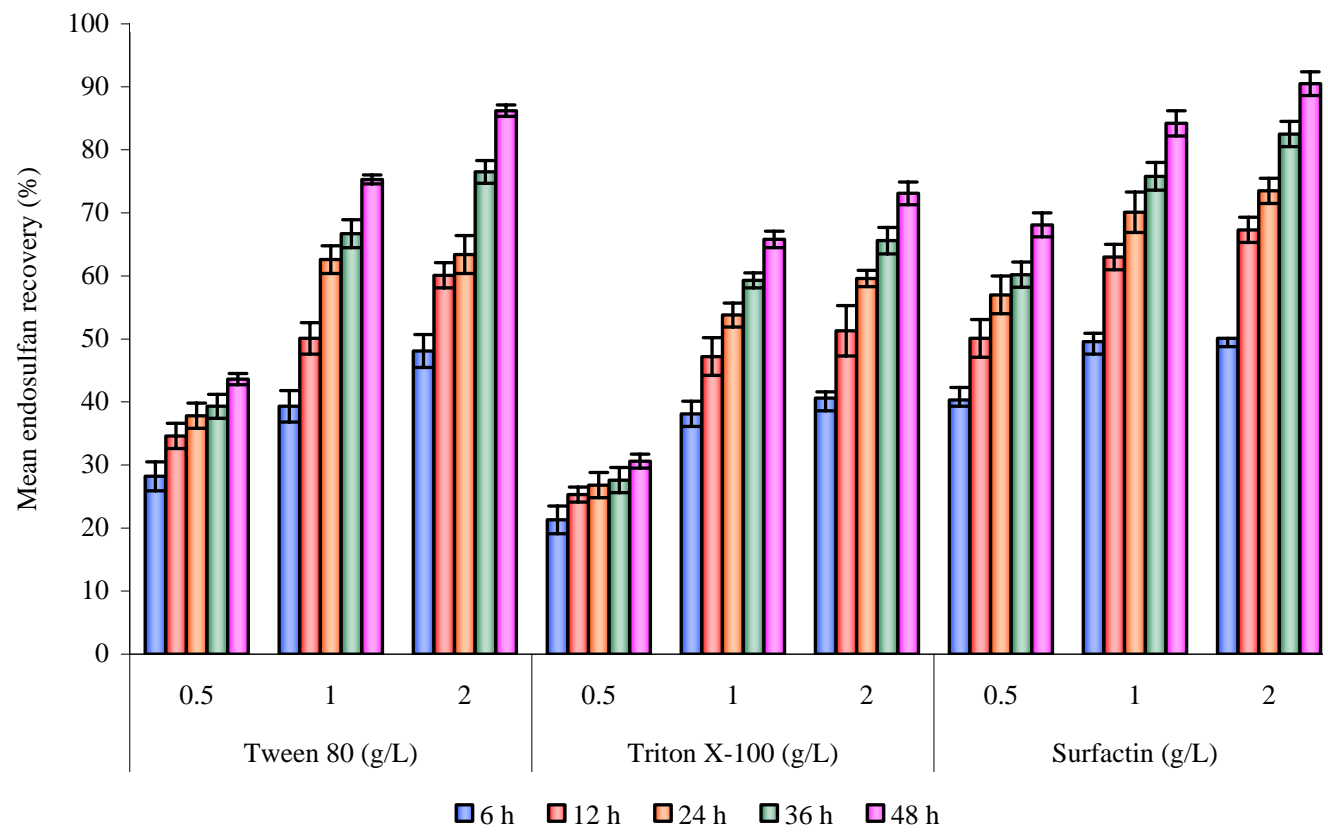

Fig. 7: Surfactants enhanced recovery of endosulfan $(160 \mathrm{mg} / \mathrm{kg})$ contaminated soil

The concentrations above the $2 \mathrm{~g} / \mathrm{L}$, the surfactants did not further increase the recovery of endosulfan possibly due to the formation of large micelles which clogged the soil micropores. When compared to $10 \mathrm{mg}$ of endosulfan per kilogram of treated soil, $160 \mathrm{mg}$ of endosulfan per $\mathrm{kg}$ of treated soil recorded 3-5 \% maximum recovery at all the surfactant concentrations and all the hours studied.

\section{DISCUSSION AND CONCLUSION}

The addition of surfactants enhanced the recovery, possibly by reducing the tortuosity of the soil organic 
Table 1: Physical and chemical characteristics of soil from, Thiruvallur District

\begin{tabular}{ll}
\hline Parameters & Values \\
\hline Bulk density (g/cc) & 1.61 \\
Moisture content (\%) & 15.07 \\
$\mathrm{pH}$ & 7.5 \\
Organic carbon (\%) & 0.12 \\
Available nitrogen (Kg/ha) & 191 \\
Available phosphorous (Kg/ha) & 25 \\
Available potassium (Kg/ha) & 65 \\
Calcium (\%) & 0.14 \\
Magnesium (\%) & 0.058 \\
Humic acid (\%) & 0.06 \\
\hline
\end{tabular}

matter (Sahoo et al., 1998). Decrease in tortuosity might be due to two mechanisms. In the first process, the addition of a surfactant to water reduces the surface tension of the water until CMC is reached (Decesare and Smith, 1994). The surfactants might have reduced the interfacial tension of the water and soil organic matter, allowing the solution to penetrate deeper into and wet the hydrophobic regions of the SOM. In the second process, the surfactants by changing the solvent chemistry, might have caused the organic matrix to swell and reduce the tortuosity (Lyon and Rhodes, 1991). The sharp enhancement of endosulfan recovery above the CMC of surfactants indicate that micelles were as explained above for more effective in solubilizing endosulfan because of the wider extent of the organic environment in pseudophase state. The inner region of the hydrophobic micellar pseudophase was capable of solubilizing endosulfan by partitioning of the compound into this region (Valsaraj and Thibodeux, 1989). This partitioning is also supported by (Edwards et al., 1991). The linear relationships between $\log \mathrm{K}_{\mathrm{mc}}$ (micelle-water partition coefficient) and $\log \mathrm{K}_{\mathrm{ow}}$ (octanol-water partition co efficient) for a variety of hydrophobic organic compounds in micellar solutions. Biosurfactant (surfactin) produced from Bacillus subtilis have greater effect on recovery of endosulfan. Biosurfactants have good potential for remediation of hydrophobic pollutants in the soil environments than chemical surfactants (Dyke et al., 1993). The biosurfactant completely eliminate the oil and other hydrophobic contaminants from contaminated area (Zhang and Miller, 1993). At concentration $2 \mathrm{~g} / \mathrm{L}$, surfactants are likely to have considerably greater impact on release of a wide range of organic pollutants, but at these concentrations the toxicity of the synthetic surfactants to the pesticides degrading microbes may reduce their effectiveness, but biosurfactants are non-toxic and eco friendly one. The observed order of recovery being surfactin $>$ Tween 80 $>$ Triton X-100. The use of surfactants in soil remediation leads to complex interactions among surfactant, soil, pollutant and microorganisms. The physical state of organic matter and variation in $\mathrm{pH}$ might have also been responsible for poor or good recovery of hydrophobic contaminants from soil. Surfactants are required to remove organic compounds from soil and for the formation of emulsions that facilitate assimilation by microorganisms and enhance the bioavailability and biodegradation of hydrophobic pollutants in soil (Volkering et al., 1993). The results from our studies demonstrate that the use of surfactants can facilitate remediation of endosulfan-contaminated soil by removing endosulfan. However, optimal surfactant concentrations for increasing the release of the compound need to be established prior to remediation, which may depend on the nature of the contaminant and the soil type.

\section{ACKNOWLEDGEMENT}

The Authors would like to thank from CSIR-New Delhi for the financial support throughout the study.

\section{REFERENCES}

Arenstein, B. N., Calvillo, V. M. and Alexander, M., (1991). Effects of surfactants at low concentrations on the desorption and biodegradation of sorbed aromatic compounds in soil. Environ. Sci. Technol., 25, 1728-1731.

Bury, S. J. and Miller, C. A., (1993). Effect of micellar solubilization on biodegradation rates of hydrocarbons. Environ. Sci. Technol., 27, 104-110.

Chopra, S. L. and Kanwar, J. S., (1982). Analytical agricultural chemistry, Kalyani publishers, New Delhi, 1621.

Dicesare, D., Smith, J. A., (1994). Surfactant effects on desorption rate of nonionic organic compounds from soil to water. Rev. Environ. Contam. Toxicol., 134, 1-29.

Dyke, M. I., Gulley, S. L., Lee, H., Trvors, J. T. and Dyke, V. M. I., (1993). Evaluation of microbiol surfactants for recovery of hydrophobic pollutants from soil. J. Indus. Microbiol., 11, 163-170.

Edwards, D. A., Luthey, R. G. and Liu, Z., (1991). Solubilization of polycyclic aromatic hydrocarbons in micellar nonionic surfactant solutions. Environ. Sci. Technol., 25, 127-133.

Jackson, M. L., (1958). Soil chemical analyses, Prentice Hall India Pvt Ltd., New Delhi, 498.

Kosaric, N., (2001). Biosurfactant and their application for soil remediation. Food Technol. Biotechnol., 39, 295-304.

Kullmann, S. W. and Matsumura, F., (1996). Metabolic pathway utilized by Phanerochaete chrysosporium for degradation of the cyclodine pesticide endosulfan. Appl. Environ. Microbiol., 62, 593-600.

Laha, S. and Luthy, R. G., (1996). Effect of nonionic surfactants on the solubilization and mineralization of phenanthrene in soil-water systems. Biotechnol. Bioeng., 62, 283-287. 
Lyon, W. G. and Rhodes, D. E., (1991). The swelling properties of organic matter and their relation to sorption of nonionic organic compounds. In the swelling properties of organic matter and their relation to sorption of nonionic organic compounds, Kerr, R. S., (Ed), Environmental Research lab, Ada, UK.

Mayer, H. P. and Fietcher, A., (1985). Production of cloned human leukocyte by Bacillus subtilis: Optimal conditions are related with restrained growth. Appl. Environ. Microbiol., 50, 5023-5027.

Miller, R. M. and Zhang, Y., (1997). Measurement of biosurfactant enhanced solubilization and biodegradation of hydrocarbons, Methods in biotechnology, Bioremediation protocols, Sheeman human press, Totowa N. J., 2, 59-66.

Moran, A. C., Olivera, N., Matita, C., Esteves, J. L. and Sineriz, F., (2000). Enhancement of hydrocarbon waste biodegradation by addition of a biosurfactant from Bacillus subtilis. Biodegradation, 11, 65-71.

Olsen, S. R., Cole, C. V., Watanbe, F. S. and Deen, L. A., (1954). Estimation of available phosphorus in soil by extraction with sodium carbonate, USDA, Circ, 939.

Paul, V. and Balasubramaniam, E., (1997). Effect of single and repeated administration of endosulfan on behaviour and its interaction with centrally acting drugs experimental animals. Environ. Toxicol. Pharmacol., 3, 151-157.

Rosen, M. J., (1989). Micelle formation of surfactants: In Micelle formation by surfactants, A wiley-Interscience publication, John Wiley and Sons, New York, 108-169.

Sahoo, D., Smith, J. A., Imbrigietta, T. E. and Mclellan, H. M., (1998). Surfactant enhanced remediation of a trichloroethane contaminated aquifer. Environ. Sci. Technol., 32, 1686-1693.

Stanford, S. and English, L., (1984). Use of flame photometer in rapid soil tests of pottasium and calcium. Agron. J. 41, 446-447.
Stevenson, F. J., (1965). Gross chemical fractionation of organic matter In: Methods of soil analysis. Part II, Black, C. A., Evens, D. D., White, J. L., Ensminger, L. E., Clark, F. E., (Eds). Amer. Soc. Agro. Madison. Wis., US, 1965.

Subbiah, B. V. and Asija, G. L., (1956). A rapid procedure for estimation of available nitrogen in soils. Curr. Sci 25, 259260.

Sunderam, R. I. M., Cheng, D. M. H. and Thomson G. B., (1992). Toxicity of endosulfan to native and introduced fish in Australia. Environ. Toxicol. Chem., 11, 14691476.

Tiehm, A., Stieber, M., Werner, P. and Frimmel, M. H., (1997). Surfactant enhanced mobilization and biodegradation of polycyclic aromatic hydrocarbons in manufactured gas plant soil. Environ. Sci. Technol., 31, 2570-2576.

Thibault, S. L., Anderson, M., Frankenberyer, W. T., (1994). Influence of surfactants on pyrene desorption and degradation in soils. Appl. Environ. Microbiol., 60, 2101-2106.

Turner, K. D., Syvamen, V. and Meizel, S., (1997). The human aerosome is highly sensitive to inhibition by cyclodine insecticides. J. Androl., 28, 571-575.

Valsaraj, K. T. and Thibodeaux, L. J., (1989). Relationship between micelle water and octanal water partition constants for hydrophobic organic compounds of environmental interest. Wat. Res 23, 183-189.

Volkering, F., Braure, A. M. and Rulkens, W. H., (1998). Microbiological aspects of surfactant use for biological soil remediation. Biodegradation, 8, 401-407.

Walkley, A. and Black, C. A. (1934). An estimation method for determination of soil organic matter and a proposed modifications of the chromic acid titration method. Soil Sci., 37, 1409-1421.

Zhang, V. and Miller, R. M. (1994). Effect of Pseudomonas rhamnolipid biosurfactant on cell hydrophobicity and biodegradation of octadecane. Appl. Environ. Microbiol., 60, 2101-2106.

\section{AUTHOR(S) BIOSKETCHES}

Jayashree, R., Ph.D., scholar in environmental studies, Anna University, Chennai, India, Email:p_tamil@yahoo.com

Vasudevan, N., Assistant professor in environmental studies, Anna University, Chennai, India. Email:annalib@sirnetm.ernet.in

Chandrasekaran, S., Professor in Entomology, Tamilnadu Agricultural University, Coimbatore, India.Email: subra_t_2000@yahoo.com

This article should be referenced as follows:

Jayashree, R., Vasudevan, N. and Chandrasekaran, S., (2006). Surfactants enhanced recovery of endosulfan from contaminated soils. Int. J. Environ. Sci. Tech., 3 (3),251-259. 